Article

\title{
Acute Effects of a Single Football Training or Match on Passive Hip Rotation Range of Motion in Semi-Professional Football Players: A Pilot Study
}

\author{
Blanca De-la-Cruz-Torres $1, *\left(\mathbb{D}\right.$, Vanesa Abuín-Porras ${ }^{2}\left(\mathbb{D}\right.$, Maria Blanco-Morales ${ }^{2}(\mathbb{D}$, \\ Mónica de-la-Cueva-Reguera ${ }^{2}$, César Calvo-Lobo ${ }^{3}\left(\mathbb{D}\right.$, Daniel López-López ${ }^{4}$ (D) and \\ Carlos Romero-Morales ${ }^{2}$ (D) \\ 1 Department of Physiotherapy, University of Seville, Avicena Street, 41009 Seville, Spain \\ 2 Faculty of Sport Sciences, Universidad Europea, Villaviciosa de Odón, 28670 Madrid, Spain; \\ vanesa.abuin@universidadeuropea.es (V.A.-P.); maria.blanco@universidadeuropea.es (M.B.-M.); \\ monica.delacueva@universidadeuropea.es (M.d.-l.-C.-R.); carlos.romero@universidadeuropea.es (C.R.-M.) \\ 3 Facultad de Enfermería, Fisioterapia y Podología, Universidad Complutense de Madrid, 28040 Madrid, \\ Spain; cescalvo@ucm.es \\ 4 Research, Health and Podiatry Group, Department of Health Sciences, Faculty of Nursing and Podiatry, \\ Universidade da Coruña, 15403 Ferrol, Spain; daniel.lopez.lopez@udc.es \\ * Correspondence: bcruz@us.es
}

Received: 19 April 2020; Accepted: 7 May 2020; Published: 10 May 2020

\begin{abstract}
Background and Objectives: The repetitive loading forces generated during football activities may induce alterations in the hip rotation range of motion (ROM) in players. The objective of this study was to evaluate the acute effects of a training and a match on bilateral passive hip rotation ROM in both lower limbs in soccer. Material and Methods: Twenty-eight male players were divided into two groups: 14 players (28 limbs) with normal bilateral hip rotation ROM (NH group) and 14 players (28 limbs) with restricted bilateral hip ROM (RH group). Passive bilateral hip rotation ROM was measured, by goniometer, before and after training or a match. Internal-rotation ROM $\left(R M_{I R}\right)$, external-rotation $\mathrm{ROM}\left(\mathrm{ROM}_{\mathrm{ER}}\right)$, total ROM $\left(\mathrm{ROM}_{\mathrm{TOT}}\right)$ and relative internal rotation $\left(\mathrm{ROM}_{\mathrm{REL}}\right)$ were calculated. Results: The NH group did not show substantial changes in hip ROM after a training nor a match. After a training session, only the RH group exhibited a substantial increase in $\mathrm{ROM}_{\mathrm{IR}}$, $\mathrm{ROM}_{\mathrm{ER}}$ and $\mathrm{ROM}_{\mathrm{TOT}}$. After a match, only the RH group exhibited a substantial increase in $\mathrm{ROM}_{\mathrm{ER}}$ and $\mathrm{ROM}_{\mathrm{TOT}}$ and exhibited a substantial decrease in $\mathrm{ROM}_{\mathrm{REL}}$. Comparing both groups, there were significant differences within ROM changes for $\mathrm{ROM}_{\mathrm{ER}}$ and $\mathrm{ROM}_{\mathrm{TOT}}$ after training and for $\mathrm{ROM}_{\mathrm{ER}}$ and $\mathrm{ROM}_{\mathrm{REL}}$ after a match. Conclusions: Despite the small sample size of the present study, the findings indicate that a single football activity leads to significant changes in hip rotation ROM in players with restricted bilateral hip external-rotation ROM. However, these changes did not reach reference cut-off scores.
\end{abstract}

Keywords: hip; soccer; load; risk factor; injury prevention

\section{Introduction}

Football is the world's most popular sport and repeated high intensity movements (including acceleration, deceleration, jumping, landing tasks and rapid changes of direction) are required during football activities [1-3]. These movements may cause an overload in the joints, generating a biomechanical imbalance that could affect their normal range of motion (ROM), both in training sessions and games. Any biomechanical alterations, especially in the lower extremity, may disturb proper motor development and cause pain when playing sports [4,5]. In this regard, Sahrmann [6] 
identifies motion as a cause of alterations and tissue damage, especially when the movement deviates from the optimal kinesiological pattern.

Because of different lower extremity demands among sports, passive hip ROM may differ by sport [7]. In football, Mosler et al. [8] proposed normal values for hip ROM in professional football players (internal rotation in prone $38 \pm 8^{\circ}$ and external rotation in supine $32 \pm 8^{\circ}$ ); Manning and Hudson [9] suggested that a specific pattern of hip ROM, measured in supine, was found in professional footballers (internal rotation in supine $25^{\circ}$ and external rotation in supine $44^{\circ}$ ), which appeared to be different from controls (internal rotation $43^{\circ}$ and external rotation $43^{\circ}$ ); López-Valenciano et al. [10] found non-clinically relevant bilateral differences $\left(>6^{\circ}\right)$ between the dominant (internal rotation $47.1 \pm 8.0^{\circ}$ and external rotation $49.9 \pm 9.8^{\circ}$ ) and non-dominant (internal rotation $45.3 \pm 7.9^{\circ}$ and external rotation $50.7 \pm 9.8^{\circ}$ ) hip joints' $\mathrm{ROM}$ average values in football players, measured in prone. Some authors $[8,9,11]$ suggested that group average ROM may distort the number of players reporting restricted $\mathrm{ROM}$ due to the fact that there is a large degree of inter-player variability in ROMs. Experts support the notion that there are football-specific adaptations in hip rotation ROM, but there are limited studies on the effect of football activities on hip ROM $[9,10]$. The restricted scores have been considered as primary risk factors for some of the most common injuries in football. Tak et al. [12] obtained that a decreased hip ROM in professional soccer players was associated with more hip- and groin-related symptoms. King et al. [13] compared the hip biomechanics associated with femoro-acetabular impingement syndrome and rotation ROM between both limbs of sub-elite football players with unilateral hip-related groin pain. They concluded that these players had less hip $\mathrm{ROM}_{\mathrm{ER}}$ and no difference in rotation $\mathrm{ROM}_{\mathrm{IR}}$. Verrall et al. [14] described a reduction in hip rotation ROM in players with chronic groin injury diagnosed as pubic bone stress injury.

Thus, it is necessary to clarify whether the repetitive loading forces generated during a single football training and/or match induce alterations in the normal and restricted hip rotation ROM in football players. This finding may help sports scientists and therapists to establish preventive programs, which include hip rotation measurements or treatments, that may be included as part of a football player's training and/or match to potentially reduce the risk of player injury.

Therefore, since rotational hip profiles have not been evaluated after a single football training session or competitive match in semi-professional male football players, the purpose of this study was to evaluate the acute effects of a training and a competitive football match on bilateral passive hip rotation ROM in the dominant and non-dominant hip of semi-professional football players.

\section{Materials and Methods}

\subsection{Participants}

The power calculation (using the $G^{*}$ Power software- version 21) was based on the total rotation variable of an initial samples $(n=8)$ with two groups (mean $\pm \mathrm{SD}$ ), 4 subjects with restricted bilateral hip ROM $(67 \pm 3.75)$ and 4 with normal bilateral hip rotation ROM $(74 \pm 4.79)$. Indeed, 1-tailed hypothesis and effect size of 1.52 and an $\alpha$ error probability of 0.05 , a power ( $1-\beta$ error probability) of $80 \%$ and an allocation ratio (N2/N1) of 1 were applied for the sample size calculation. Therefore, a total sample size of 14 subjects was calculated.

Twenty-eight semi-professional male football players from Spanish honor division clubs volunteered for the study (Table 1). In each participant, the hip rotation ROM scores were categorized as normal or restricted according to the reference values previously reported to consider an athlete as being more prone to suffer an injury $[15,16]$. ROM values were reported as restricted according to the following cut-off scores: $<35^{\circ}$ for the $\mathrm{ROM}_{\mathrm{ER}}$ [17]. They were divided into two groups: one made up of 14 players (28 limbs) with normal bilateral hip rotation ROM (NH group) and the other made up of 14 players (28 limbs) with restricted bilateral hip $\mathrm{ROM}_{\mathrm{RE}}(\mathrm{RH}$ group). 
Table 1. Demographic features of the sample.

\begin{tabular}{|c|c|c|c|c|}
\hline TitData & $\begin{array}{c}\text { Total Sample } \\
(n=28 \text { players; } 56 \text { limbs })\end{array}$ & $\begin{array}{c}\text { Normal Hip } \\
\text { (NH Group) } \\
(n=14 \text { players; } 28 \text { limbs })\end{array}$ & $\begin{array}{c}\text { Restricted Hip } \\
\text { (RH Group) } \\
(n=14 \text { players; } 28 \text { limbs })\end{array}$ & $p$ Values \\
\hline Mean Age (years) & $25(4.30)$ & $26(4.76)$ & $24(4.04)$ & 0.36 \\
\hline Height (cm) & $181.00(0.03)$ & $183.00(0.03)$ & $181.00(0.04)$ & 0.39 \\
\hline Weight (kg) & $76.71(5.90)$ & $77.44(5.92)$ & $75.21(5.94)$ & 0.18 \\
\hline Body Mass Index & $22.14(4.94)$ & $23.19(1.41)$ & $21.50(6.14)$ & 0.43 \\
\hline Football Years & $19.42(4.68)$ & $20.11(4.37)$ & $19.00(4.97)$ & 0.58 \\
\hline
\end{tabular}

Data are reported as mean (SD).

An initial examination by the sport doctor focused on orthopedic and other conditions that might preclude study, and all the participants were found to be in good health (for example, structural abnormalities were refused). Inclusion criterion for the NH group included: (i) a minimum of 10-years football experience; (ii) semi-professional level; and (iii) no low back or lower extremity injury in the previous 3 months. For the RH group, the inclusion criteria were: (i) a minimum of 10-years football experience; (ii) semi-professional level; (iii) restricted bilateral hip $\mathrm{ROM}_{\mathrm{RE}}$, caused by an imbalance between the internal and external rotator muscles and characterized by a shortening of the internal rotator muscles [6] (this imbalance is due to a lack of stretching of the hip muscles and lumbopelvic exercise that keeps the hip joint balanced [6]) and (iv) functional alteration of the hip. Exclusion criterion included: (i) having musculoskeletal injuries during the previous three months; (ii) current active disease processes; (iii) structural alteration of the hip; or (iv) previous surgery.

\subsection{Ethics}

The study was approved by the ethics committee of the University Hospital Virgen Macarena-Virgen del Rocio (19 June 2019) in accordance with the Declaration of Helsinki. Before enrolling, the subjects were fully informed about the protocol and a written informed consent was obtained.

\subsection{Testing Procedures}

All passive bilateral hip ROM measurements were carried out by an experienced physiotherapist with more than 10 years of experience. The examiner was blind to the group assignment and the mean of the two values of each variable was used for the corresponding analysis. All variables were obtained using a universal goniometer, as previously described [8]. All players were positioned prone with the hip in $0^{\circ}$ of extension and $30^{\circ}$ of abduction. This neutral hip positioning minimized muscular involvement. The knee was flexed to $90^{\circ}$. The leg was passively rotated internally and externally until initial sacral tilt as determined by the physiotherapist's palpation. At this point, the transverse angle formed by true vertical and the tibial diaphysis were considered $R O M_{E R}$ and $R O M_{I R}$, respectively. ROM factor most consistently related to groin pain in athletes [18]. The subtracted $R M_{E R}$ from $R O M_{I R}$ was used to calculate $R O M_{R E L}$. This relative $R O M_{I R}$ variable retained the original degree unit and has been used in the literature to represent the amount of bias toward $\mathrm{ROM}_{\mathrm{IR}}$ [19]. All tests were performed before and after a training session or official match. The initial measurements were evaluated before the warm-up of the training or match and the final scores were measured just after training or the match (the examiner took no more than $5 \mathrm{~min}$ ).

\subsection{Statistical Analysis}

The normality of the data distribution was verified by the Shapiro-Wilk test. Descriptive statistics $($ mean $\pm \mathrm{SD}$ ) for the different variables were calculated. Paired $t$ tests confirmed no appreciable differences in bilateral $\mathrm{ROM}_{\mathrm{IR}}$ or $\mathrm{ROM}_{\mathrm{ER}}$. 
Repeated-measures analysis of variance (ANOVA) with 2 factors, 2 (group) $\times 2$ (time: pre-training and post-training), were performed for $R O M_{I R}, R_{E R}, R O M_{T O T}$ and $R O M_{R E L}$. To interpret the effect size (ES) results, Cohen suggested that $d=0.02$ was considered "small", $d=0.5$ was considered "medium" and a $d=0.8$ was considered a "large" effect size [20].

The intraclass correlation coefficient (ICC) and the standard error of measurements (SEM = SD $/ \sqrt{ } n$ ) were used to determine the intra-observer reliability of the measurements.

\section{Results}

All football players were healthy and competing at the time of the trial, training and playing a total of $12 \mathrm{~h}$ per week of football and having a previous average football experience of $19.42 \pm 4.69$ years.

There were no significant baseline differences between both groups in any participant characteristics variables (Table 1). There were also no differences between the duration of training and the match (warm up + training: $108.75 \pm 6.66 \mathrm{~min}$; and warm up + match: $112.00 \pm 10.69 \mathrm{~min}, p=0.26$ ).

\subsection{Internal Rotation}

Variations in hip $\mathrm{ROM}_{\mathrm{IR}}$ of each group after the training or match are presented in Tables 2 and 3. The NH group did not show substantial changes after training nor the match. The RH group showed significant differences after training $(p=0.01 ; d=0.6)$ but not after the match.

Table 2. Relative differences and qualitative outcomes in passive hip rotation measurements for both limbs after training.

\begin{tabular}{ccccc}
\hline Variable & Pre-Training & Post-Training & $p$ Value & Effect Size (d) \\
\hline NH Group & & & & \\
$\operatorname{ROM}_{\mathrm{IR}}\left({ }^{\circ}\right)$ & $37 \pm 4.27$ & $38 \pm 5.02$ & 0.59 & 0.2 \\
$\operatorname{ROM}_{\mathrm{ER}}\left({ }^{\circ}\right)$ & $37 \pm 2.20$ & $35 \pm 3.48$ & 0.23 & 0.7 \\
$\operatorname{ROM}_{\mathrm{TOT}}\left(^{\circ}\right)$ & $74 \pm 4.79$ & $74 \pm 6.32$ & 0.95 & 0.0 \\
$\operatorname{ROM}_{\mathrm{REL}}\left(^{\circ}\right)$ & $1 \pm 4.81$ & $2 \pm 5.90$ & 0.38 & 0.2 \\
\hline RH Group & & & & \\
$\operatorname{ROM}_{\mathrm{IR}}\left({ }^{\circ}\right)$ & $37 \pm 2.64$ & $39 \pm 3.64$ & 0.01 & 0.6 \\
$\operatorname{ROM}_{\mathrm{ER}}\left(^{\circ}\right)$ & $29 \pm 2.44$ & $34 \pm 3.38$ & 0.001 & 1.96 \\
$\operatorname{ROM}_{\mathrm{TOT}}\left(^{\circ}\right)$ & $67 \pm 3.75$ & $73 \pm 4.89$ & $<0.001$ & 1.37 \\
$\operatorname{ROM}_{\mathrm{REL}}\left(^{\circ}\right)$ & $9 \pm 4.31$ & $6 \pm 4.74$ & 0.07 & 0.7 \\
\hline
\end{tabular}

Data are reported as mean \pm standard deviation (SD). $\mathrm{ROM}_{\mathrm{IR}}$ : range of motion of internal rotation; $\mathrm{ROM}_{\mathrm{ER}}$ : range of motion of external rotation; $\mathrm{ROM}_{\mathrm{TOT}}$ : total rotation; $\mathrm{ROM}_{\mathrm{REL}}$ : relative internal rotation. Level of significance $p<0.05$.

Table 3. Relative differences and qualitative outcomes in passive hip rotation measurements for both limbs after a match.

\begin{tabular}{|c|c|c|c|c|}
\hline Variable & Pre-Match & Post-Match & $p$ Value & Effect Size (d) \\
\hline \multicolumn{5}{|l|}{ NH Group } \\
\hline $\mathrm{ROM}_{\mathrm{IR}}\left(^{\circ}\right)$ & $40 \pm 3.19$ & $41 \pm 5.01$ & 0.66 & 0.2 \\
\hline $\operatorname{ROM}_{\mathrm{ER}}\left(^{\circ}\right)$ & $36 \pm 1.87$ & $35 \pm 2.84$ & 0.32 & 0.4 \\
\hline $\mathrm{ROM}_{\mathrm{TOT}}\left({ }^{\circ}\right)$ & $76 \pm 3.97$ & $76 \pm 6.43$ & 0.89 & 0.0 \\
\hline $\operatorname{ROM}_{\text {REL }}\left(^{\circ}\right)$ & $4 \pm 3.41$ & $5 \pm 5.01$ & 0.23 & 0.2 \\
\hline \multicolumn{5}{|l|}{ RH Group } \\
\hline $\operatorname{ROM}_{\mathrm{IR}}\left(^{\circ}\right)$ & $38 \pm 3.84$ & $37 \pm 4.22$ & 0.90 & 0.3 \\
\hline $\operatorname{ROM}_{\mathrm{ER}}\left({ }^{\circ}\right)$ & $29 \pm 3.32$ & $32 \pm 2.79$ & 0.003 & 1.0 \\
\hline $\mathrm{ROM}_{\mathrm{TOT}}\left(^{\circ}\right)$ & $68 \pm 5.31$ & $69 \pm 5.81$ & 0.03 & 0.2 \\
\hline $\operatorname{ROM}_{\mathrm{REL}}\left(^{\circ}\right)$ & $8 \pm 4.84$ & $5 \pm 4.17$ & 0.05 & 0.7 \\
\hline
\end{tabular}

Data are reported as mean \pm standard deviation $(\mathrm{SD}) . \mathrm{ROM}_{\mathrm{IR}}$ : range of motion of internal rotation; $\mathrm{ROM}_{\mathrm{ER}}$ : range of motion of external rotation; $\mathrm{ROM}_{\mathrm{TOT}}$ : total rotation; $\mathrm{ROM}_{\mathrm{REL}}$ : relative internal rotation. Level of significance $p<0.05$. 
No differences were observed after training or the match in $\mathrm{ROM}_{\mathrm{IR}}$ changes between groups (Table 4). The ICC and SEM were 0.94 and 2.89, respectively, for the hip ROM IR measurements, indicating high reliability.

Table 4. Results from the between-group analysis in hip rotation ROMs.

\begin{tabular}{ccc}
\hline \multicolumn{2}{c}{ Between Group Mean Difference of Changes in ROMs } \\
\hline NH Group vs. RH Group & Training & Match \\
\hline $\operatorname{ROM}_{\mathrm{IR}}\left({ }^{\circ}\right)$ & $p=0.27 ; d=0.2$ & $p=0.53 ; d=0.9$ \\
$\operatorname{ROM}_{\mathrm{ER}}\left({ }^{\circ}\right)$ & $p=0.001 ; d=0.3$ & $p=0.01 ; d=1.1$ \\
$\operatorname{ROM}_{\mathrm{TOT}}\left({ }^{\circ}\right)$ & $p=0.006 ; d=0.2$ & $p=0.35 ; d=1.1$ \\
$\operatorname{ROM}_{\mathrm{REL}}\left({ }^{\circ}\right)$ & $p=0.36 ; d=0.7$ & $p=0.03 ; d=0.2$ \\
\hline
\end{tabular}

Standard changes in mean $(90 \% \mathrm{CL})$. $\mathrm{ROM}_{\mathrm{IR}}$ : range of motion of internal rotation; $\mathrm{ROM}_{\mathrm{ER}}$ : range of motion of external rotation; $\mathrm{ROM}_{\mathrm{TOT}}$ : total rotation; $\mathrm{ROM}_{\mathrm{REL}}$ : relative internal rotation. Level of significance $p<0.05$.

\subsection{External Rotation}

Variations in hip $\mathrm{ROM}_{\mathrm{ER}}$ of each group after the training or match are presented in Tables 2 and 3. The NH group did not show substantial changes after the training nor match. The $\mathrm{RH}$ group showed significant differences after the training $(p=0.001 ; d=2.0)$ and match $(p=0.003 ; d=1.0)$.

Differences were observed after the training $(p=0.001 ; d=0.3)$ and match $(p=0.01 ; d=1.1)$ in $\mathrm{ROM}_{\mathrm{ER}}$ changes among the groups (Table 4). The ICC and SEM were 0.85 and 2.18, respectively, for the hip $\mathrm{ROM}_{\mathrm{ER}}$ measurements, indicating good reliability.

\subsection{Total Rotation}

Variations in hip $\mathrm{ROM}_{\mathrm{TO}}$ of each group after the training or match are presented in Tables 2 and 3. The NH group did not show substantial changes after the training nor match. The RH group showed significant differences after the training $(p=0.001 ; d=1.4)$ and match $(p=0.03$; $d=0.2$.

Differences were observed after training $(p=0.006 ; d=0.2)$ in $\mathrm{ROM}_{\mathrm{TOT}}$ changes among the groups. However, no differences were observed after the match between groups (Table 4). The ICC and SEM were 0.85 and 4.21 , respectively, for the hip $\mathrm{ROM}_{\mathrm{TR}}$ measurements, indicating good reliability.

\subsection{Relative Internal Rotation}

Variations in hip $\mathrm{ROM}_{\mathrm{REL}}$ of each group after the training or match are presented in Tables 2 and 3. The NH group did not show substantial changes after the training nor match. The RH group showed significant differences after the match $(p=0.05, d=0.7)$ but not after training.

No differences were observed after training in $\mathrm{ROM}_{\mathrm{REL}}$ changes between both groups. However, differences were observed after the match between groups $(p=0.03 ; d=0.0)$ (Table 4 ). The ICC and SEM were 0.94 and 4.15 , respectively, for the hip ROM REL measurements, indicating high reliability.

\section{Discussion}

The main finding of this study was that football activities mainly affected the hip rotation ROMs of players with restricted hip $\mathrm{ROM}_{\mathrm{ER}}$. On the one hand, a football training session induces an immediate elevation in $\mathrm{ROM}_{\mathrm{IR}}$ (moderate ES), ROM $\mathrm{ER}$ (large ES) and ROM $\mathrm{TOT}$ (large ES) in the RH group. However, the data only obtained normal values of total rotation due to the increase in internal rotation after training. On the other hand, a football match induces an immediate elevation in $\mathrm{ROM}_{\mathrm{ER}}$ (large ES) and $\mathrm{ROM}_{\mathrm{TOT}}$ (small ES) as well as an immediate decrease in $\mathrm{ROM}_{\mathrm{REL}}$ (moderate ES) in the RH group. In this case, the data did not obtain normal values of $\mathrm{ROM}_{\mathrm{ER}}$ and $\mathrm{ROM}_{\mathrm{TOT}}$ because there were no changes in $\mathrm{ROM}_{\mathrm{IR}}$ (Tables 2 and 3). Therefore, the functional alteration of the hip in the players with restricted hip $\mathrm{ROM}_{\mathrm{EM}}$ was maintained during football activities. These data demonstrate that 
players with restricted bilateral hip $R_{\mathrm{RE}}$ maintained their pathological values despite the fact that football activities improve hip rotation ROMs due to tissue warming. Therefore, players maintain an alteration of movement in the hip that may be more predisposing to injuries during training or a match. In fact, there were significant mean differences of changes in favor of the $\mathrm{NH}$ group, both after training and the match (Table 4). We suggest that football activities caused changes in the hip rotation ROM in players with restricted bilateral hip $\mathrm{ROM}_{\mathrm{RE}}$, and that these changes were enough to reach normal ROM values. Altered movement patterns exposed repetitive and high loading forces generated during sports have been suggested to contribute to a variety of musculoskeletal pain conditions [12-14]. Therefore, these players were at risk of injury, mainly after a match. According to Sahrmann [6], authors suggest that the cumulative effect of repetitive actions (especially when their performance deviates from the optimal kinesiological pattern) causes tissue damage. Furthermore, authors hypothesize that musculoskeletal disorders of a mechanical origin may be relieved and prevented by correcting motion patterns and tissue adaptations. Therefore, these findings highlight the relevance of measuring the hip rotation before football trainings and matches in order to keep hip health.

In recent years, increasing evidence is now demonstrating that it is necessary to identify biomechanical deficiencies in the joints before sport activities. Accordingly, studies have now been published on the role of the hip ROMs in different sports. They tried to correlate these parameters with the development of subsequent injuries. Li et al. [21] showed higher rates of hip, groin and hamstring injuries in players with decreased hip internal rotation. King et al. [11] identified that football players with unilateral hip-related groin pain had less hip $R O M_{E R}$ and no difference in rotation $R O M_{I R}$. Tak et al. [10] suggested that a decreased hip ROM in professional soccer players was associated with more hip- and groin-related symptoms. Nevertheless, limitations in the range of hip movement may have negative effects on distal joints. Verrall et al. [12] described a reduction in hip ROM was evident in athletes with chronic groin injury diagnosed as pubic bone stress injury. Scher et al. [22] correlated altered hip ROM with shoulder injuries in professional pitchers and Saito et al. [23] found that a decreased hip flexion and internal rotation (IR) were risk factors for elbow pain. We hypothesized that the hips are a key component to performance and injury risk.

Although the relationship between hip ROM and injuries is gaining interest, the understanding of the evolution of hip ROM after trainings, after matches or over the course of the football season remains limited. Accordingly, our results showed that a football training session or match induced an acute increase of the $\mathrm{ROM}_{\mathrm{ER}}$, yet $\mathrm{ROM}_{\mathrm{ER}}$ did not reach the normal range in those with baseline

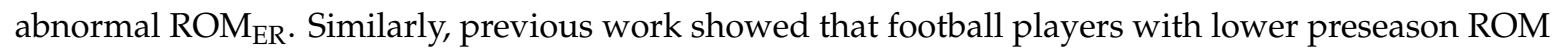
in the hip flexors and knee flexors had a higher risk for muscle injuries to these muscle groups [24]. Paul et al. [25] obtained that a threshold may exist in which match play load negatively impacts hip flexibility. Verral et al. [26] suggested that a reduced total hip joint ROM is associated with later development of chronic groin injury and as such may be a risk factor. Screening of flexibility for football players should be conducted before football activities, and flexibility training should be mainly prescribed to players with reduced ROM to lower the risk of developing a muscle injury.

This study contains limitations that require acknowledgment. First, the only time-point selected to measure passive hip rotation ROM in response to a single football training or match was immediately post-training or post-match. Future studies should evaluate these variables using several time-points (until the next training) after the football activities. Second, it would be interesting to know the internal load caused by the training or the match and relate it to the changes of rotation in hip ROM. Third, a small sample was used, but this is often something that cannot be overcome when studying semi-professional football players with restricted bilateral hip $\mathrm{ROM}_{\mathrm{RE}}$.

\section{Conclusions}

A single football training session or match leads to significant changes in hip rotation ROMs in players with restricted bilateral hip $\mathrm{ROM}_{\mathrm{RE}}$. However, these changes did not reach normal values. According to the study, these findings may suggest an unstable hip joint with a predisposition to 
musculoskeletal injuries and screening of hip flexibility for football players before football activities to prevent injuries.

Author Contributions: Conceptualization, B.D.-1.-C.-T.; data curation, B.D.-1.-C.-T., D.L.-L. and V.A.-P.; methodology, M.B.-M., M.d.-l.-C.-R., C.C.-L.; formal analysis, C.R.-M., C.C.-L. and D.L.-L.; investigation, C.R.-M., V.A.-P., M.B.-M. and M.d.-1.-C.-R.; supervision, B.D.-1.-C.-T. and C.R.-M.; writing-original draft preparation, B.D.-1.-C.-T.; writing-review and editing, B.D.-1.-C.-T. and C.R.-M. All authors have read and agreed to the published version of the manuscript.

Funding: This research received no external funding.

Conflicts of Interest: The authors declare no conflict of interest.

\section{References}

1. Krustrup, P.; Aagaard, P.; Nybo, L.; Petersen, J.; Mohr, M.; Bangsbo, J. Recreational football as a health promoting activity: A topical review. Scand. J. Med. Sci. Sport 2010, 20 (Suppl. 1), 1-13. [CrossRef]

2. Naser, N.; Ajmol, A.; Macadam, P. Physical and physiological demands of futsal. J. Exerc. Sci. Fit. 2017, 15, 76-80. [CrossRef]

3. Longo, U.G.; Sofi, F.; Candela, V.; Dinu, M.; Cimmino, M.; Massaroni, C.; Schena, E.; Denaro, V. Performance activities and match outcomes of professional soccer teams during the 2016/2017 Serie A Season. Medicina 2019, 55, 469. [CrossRef] [PubMed]

4. Arnason, A.; Sigurdsson, S.B.; Gudmundsson, A.; Holme, I.; Engebretsen, L.; Bahr, R. Risk factors for injuries in football. Am. J. Sports Med. 2004, 32 (Suppl. 1), 5S-16S. [CrossRef] [PubMed]

5. Ekstrand, J.; Gillquist, J. Soccer injuries and their mechanisms: A prospective study. Med. Sci. Sport Exerc. 1982, 15, 267-270. [CrossRef]

6. Sahrmann, S.A. Diagnosis and Treatment of Movement Impairment Syndromes, 1st ed.; Mosby: St. Louis, MO, USA, 2002.

7. Hogg, J.A.; Schmitz, R.J.; Nguyen, A.D.; Schultz, S.J. Passive hip range-of-motion values across sex and sport. J. Athl. Train. 2018, 53, 560-567. [CrossRef] [PubMed]

8. Mosler, A.B.; Crossley, K.M.; Thorborg, K.; Whiteley, R.J.; Weir, A.; Serner, A.; Hölmich, P. Hip strength and range of motion: Normal values from a professional football league. J. Sci. Med. Sport 2017, 20, 339-343. [CrossRef] [PubMed]

9. Manning, C.; Hudson, Z. Comparison of hip joint range of motion in professional youth and senior team footballers with age-matched controls: An indication of early degenerative change? Phys. Ther. Sport 2009, 10, 25-29. [CrossRef] [PubMed]

10. López-Valenciano, A.; Ayala, F.; Vera-García, F.J.; de Ste Croix, M.; Hernández-Sánchez, S.; Ruiz-Pérez, I.; Cejudo, A.; Santonja, F. Comprehensive profile of hip, knee and ankle ranges of motion in professional football players. J. Sports Med. Phys. Fit. 2019, 59, 102-109. [CrossRef]

11. Rahnama, N.; Lees, A.; Bambaecichi, E. A comparison of muscle strength and flexibility between the preferred and non-preferred leg in English soccer players. Ergonomics 2005, 48, 1568-7155. [CrossRef]

12. Tak, I.; Glasgow, P.; Langhout, R.; Weir, A.; Kerkhoffs, G.; Agricola, R. Hip range of motion is lower in professional soccer players with hip and groin symptoms or previous injuries, independent of cam deformities. Am. J. Sports Med. 2016, 44, 682-688. [CrossRef] [PubMed]

13. King, M.G.; Semciw, A.I.; Hart, H.F.; Schache, A.G.; Middleton, K.J.; Heerey, J.J.; Agricola, R.; Crossley, K.M. Sub-elite football players with hip-related groin pain and a positive flexion, adduction, and internal rotation test exhibit distinct biomechanical differences compared with the asymptomatic side. J. Orthop. Sports Phys. Ther. 2018, 48, 584-593. [CrossRef] [PubMed]

14. Verrall, G.M.; Hamilton, I.A.; Slavotinek, J.P.; Oakeshott, R.D.; Spriggins, A.J.; Barnea, P.G.; Fon, G.T. Hip joint range of motion reduction in sports-related chronic groin injurydiagnosed as pubic bone stress injury. J. Sci. Med. Sport 2005, 8, 77-84. [CrossRef]

15. Holla, J.F.; van der Leeden, M.; Roorda, L.D.; Bierma-Zeinstra, S.M.; Damen, J.; Dekker, J.; Steultjens, M.P. Diagnostic accuracy of range of motion measurements in early symptomatic hip and/or knee osteoarthritis. Arthritis Care Res. 2012, 64, 59-65. [CrossRef]

16. Roach, S.; San Juan, J.G.; Suprak, D.N.; Lyda, M. Concurrent validity of digital inclinometer and universal goniometer in assessing passive hip mobility in healthy subjects. Int. J. Sports Phys. Ther. 2013, 8, 680-688. 
17. L'hermette, M.; Polle, G.; Tourny-Chollet, C.; Tourny-Chollet, C.; Dujardin, F. Hip passive range of motion and frequency of radiographic hip osteoarthritis in former elite handball players. Br. J. Sport Med. 2006, 40, 45-49. [CrossRef]

18. Tak, I.; Engelaar, L.; Gouttebarge, V.; Barendrecht, M.; Van den Heuvel, S.; Kerkhoffs, G.; Langhout, R.; Stubbe, J.; Weir, A. Is lower hip range of motion a risk factor for groin pain in athletes? A systematic review with clinical applications. Br. J. Sports Med. 2017, 51, 1611-1621. [CrossRef]

19. Howard, J.S.; Fazio, M.A.; Mattacola, C.G.; Uhl, T.L.; Jacobs, C.A. Structure, sex, and strength and knee and hip kinematics during landing. J. Athl. Train. 2011, 46, 376-385. [CrossRef]

20. Leppink, J.; O’Sullivan, P.; Winston, K. Effect size-large, medium, and small. Perspect. Med. Educ. 2016, 5, 347-349. [CrossRef]

21. Li, X.; Ma, R.; Zhou, H.; Thompson, M.; Dawson, C.; Nguyen, J.; Coleman, S. Evaluation of hip internal and external rotation range of motion as an injury risk factor for hip, abdominal and groin injuries in professional baseball players. Orthop. Rev. 2015, 7, 111-115. [CrossRef]

22. Scher, S.; Anderson, K.; Weber, N.; Bajorek, J.; Rand, K.; Bey, M.J. Associations among hip and shoulder range of motion and shoulder injury in professional baseball players. J. Athl. Train. 2010, 45, 191-197. [CrossRef] [PubMed]

23. Saito, M.; Kenmoku, T.; Kameyama, K.; Murata, R.; Yusa, T.; Ochiai, N.; Kijima, T.; Takahira, N.; Fukushima, K.; Ishige, N.; et al. Relationship between tight- ness of the hip joint and elbow pain in adolescent baseball players. Orthop. J. Sports Med. 2014, 2, 2325967114532424. [PubMed]

24. Bradley, P.S.; Portas, M.D. The relationship between preseason range of motion and muscle strain injury in elite soccer players. J. Strength Cond. Res. 2007, 21, 1155-1159. [PubMed]

25. Paul, D.J.; Nassis, G.P.; Whiteley, R.; Marques, J.B.; Kenneally, D.; Chalabi, H. Acute responses of soccer match play on hip strength and flexibility measures: Potential measure of injury risk. J. Sports Sci. 2014, 32, 1318-1323. [CrossRef]

26. Verrall, G.M.; Slavotinek, J.P.; Barnes, P.G.; Esterman, A.; Oakeshott, R.D.; Spriggins, A.J. Hip joint range of motion restriction precedes athletic chronic groin injury. J. Sci. Med. Sport 2007, 10, 463-466. [CrossRef]

(C) 2020 by the authors. Licensee MDPI, Basel, Switzerland. This article is an open access article distributed under the terms and conditions of the Creative Commons Attribution (CC BY) license (http://creativecommons.org/licenses/by/4.0/). 